DOI 10.22394/1818-4049-2017-79-2-84-91

УДК 130.2

\title{
В.Н. Шиян
}

\section{О социадьно-культурных укдадах жизни яюдей: взгдяд на метододогические аспекты иссдедования России}

Социальность укладов жизнедеятельности людей определяется, в первую очередь, их наличным составом, качественньии характеристиками жизнедеятельности: образов и стилей жизни, поведения, традииий и обычаев, иенностей и ориентиров, приоритетов, а также многими другими компонентами, входяшими в миры населения конкретных территорий и функционирующих там сообществ. Динамика общественных отношений детерминирует изменчивость соииальньх укладов соответственно с присущими им закономерностями и формирующилися в этих условиях особенностями развития. В современных условиях мироструктурных преобразований актуальными темами стали исследования в области иивилизаиионных, планетарных, глобальных и других ммасштабных трансформаиий, включаюших в себя воспроизводственные, миграционные, этнические и другие социальные процессы. Для конкретных территорий и сообществ они расслатриваются в ралках базисных: стратегических, ресурсных, магистральных, жизнеобеспечиваюших, культурообразуюших и т.n. компонентов. Не являются исключением в данном отношении Россия и её Дальний Восток, практика вхождения их в мировое сообщество.

The sociality of ways of activity of people is determined, first of all, by their composition, qualitative characteristics of activity: images and lifestyles, behavior, traditions and customs, values and reference points, priorities, and also many other components entering the worlds of population of the specific territories and the communities functioning there. Dynamics of the public relations determines variability of social ways according to the regularities inherent in them and created in these conditions features of development. In the modern conditions of the world structure reformations researches in the field of civilization, planetary, global and other "scale" transformations including reproduction, migratory, ethnic and the other social processes became hot topics. For the specific territories and communities they are considered within the basis: strategic, resource, trunk, life-supporting, culture and the other components. Also Russia, its Far East, practice of their entrance in the world community isn't an exception in this relation.

Ключевые слова: жизнь человека, уклад жизни, жизнедеятельность людей, миры человека, мир обиества, открытый мир российского человека.

Keywords: human life, tenor of life, activity of people, patterns of the person, society patterns, open world of the Russian person.

1. Актуальность методологических исследований социально-куцьтурных укцадов жизни Аюдей. Такая потребность актуализируется в современных условиях несколькими обстоятельствами. Под воздействием научно-технологического прогресса (создание компьютернњг и телекоммуникационньг сетей, не имею- щих национальньх границ, упрощения и повышения доступности информации, увеличения её общей массы и способов обмена ею, роста уровня образования чемовечества, его физической и социальной подвижности и пр.), значительного возрастания факторов политико-культурной и экономико-институциональной экспан-

Шиян Виктор Никитович - канд. филос. наук, доцент кафедры философии, истории, государства и права, Дальневосточный институт управления - филиал РАНХиГС (г. Хабаровск). Тел.: (4212) 315975 
сии и др. в последние десятиметия общественной жизни в большей части стран существенно "разрослись" процессы глобализации, охватившие не только геополитические и экономические, финансовые его структуры $[11$, с. 381$]$. Гцобализация пронизывает и другие уровни культуры, включая уклады жизнедеятемьности, преодомевая традиционные границы функционирования стран и народов, создавая тем самым специфические трансрраничные, в т.ч. транзитивные, состояния. В этих условиях «зелая методомогия исследований общества впомне обоснованно ожидает возникновение социамьных инноваиий, выражаюшихся в формировании новьг традиций, обычаев, ценностей и другого инструментария функционирования социальных укмадов, что регулярно обнаруживается в семейной, поведенческой, коммуншкационной и другой практике организации жизнедеятельности населения многих территорий и континентов нашей планеты, которые, кстати, происходят не только под воздействием процессов гмобализации.

Потребность исследования социамьнокумьтурных укцадов актуализируется и под вциянием самой динамики жизнедеятельности: обших изменений научных и житейских представмений о феномене жизни, самоиенности жизни мюдей, значимости мер по созданию благоприятньгх безопасных предпосыцок дия воспроизводства человека, совершенствования здорового образа его жизни и нормативньх стилей жизни, формирования достойньгх современным усмовиям идеалов и других направменностей (тенденций) неистоиительного движения в будушее. Эти, как и многие другие, исследоватемьские и практические задачи находятся в центре внимания современной российской "жизнедеятемьностной" науки и практики.

Актуализируются и специфические задачи, обусловленные требованиями, возникаюшщми под воздействием "вызовов времени" и формирования проблем "исторической ответственности" национальных икол, международных ассоииаиий и т.п. социальных институтов, участвующих в разработке стратегических нормативных инструментов жизнедеятемьности человечества. В настоя- щее время наукой ставятся вопросы о необходимости расширения социальных "параметров" развития человека и общества, сформулированных ещё в Новое и нескомько более позднее время (Ф. Бэкон, Г. Гегемь, К. Маркс, О. Конт, Г. Спенсер и др.), и признания потребности выдвижения на "первый план" не только знания как такового, но и других возможностей сохранения и развития жизни, поскольку прежние идеи социальности и соииальной жизни представмены сейчас суиественно в лозунговой форме и приобреми к настоящему времени эмементы анахронизма [12]. В системе социальных и гуманитарньх исследований сложилась ситуация, близкая к временам XVIII - XIX вв., когда в методомогии значитемьным "спросом" помьзовались как методы анамиза, так и синтеза, когда её разработки охватывали как соииальную статику, так и соииальную динамику и т.п. анамогии, хотя исследованию при этом подвергаются принципиально иные проблемы. Сегодня нередки факты предможений по разработке концептов политической арифметики, соииальной физики ими биологической математики. Круг тем, интересующих российских учёных в этих условиях и взятых под угиом зрения соииальной синергетической проблематики, акцентируется вопросами катастроф, режимов с обострением, переходных и транзитивных процессов, трансцендентньх и трансцендентальньгх явцений, инноваций [2].

Имеются и другие обстоятемьства, обуслов ивающие актуамьность обращения к проблематике социамьных укмадов. Из них в специальном внимании нуждается уточнение функциональных методомогических аспектов понимания (предметной трактовки) термина соииального уклада. Содержательно уклады восходят к понятиям уложить, положить, выражая действия, бмизкие по смыслу к терминам уладить, упорядочить, обозначить некоторую последовательность прохождения событий во времени, в пространстве иии в состояниях (процессах). Они используются в прямом и перенос-

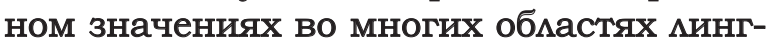
вистической практики.

Укладами обозначают значительные структурные, функциональные и 
другие события, выразившиеся в истории жизнедеятельности мюдей и ставшие своеобразными единицами отсчёта крупных этапов её развития. Они могут означать такие единицы, сформировавшиеся в истории "естественњым" путем на основе самой "природъи отражаемых общественных процессов, мибо быть интуитивно иАи осознанно сконструированнъции в процессе функционирования ихспецифических социально-кумьтурньх субъектов. Превосходно отражены уклады в источниках, описывающих в художественной форме жизнедеятельность народов: социальные, политические, территориальные, этнические и другие события истории человечества. В последние десятилетия в методомогии науки активно и плодотворно разрабатывается вопрос о технологических, информационных и некоторых других укладах. Сам уклад как процесс чередования происходящих событий выполняет роль ритмообразующей функции, вкмючающей в себя общественные, естественные, социальные, психологические и другие организационные факторы. В процессе функционирования укладов происходит своеобразный "отбор" таких факторов и "отработка" механизмов их взаимодействия и деятельности.

Социально-культурные уклады включают в себя:

- социальные компоненты как основу их мирообразуюших композиционных (организационных) составов, а также присущих им социальных потребностей, интересов, ценностей, смыслов, идеалов и ряда других нормативов;

- субстратный фактор как основу их "технологического" (артефактного, искусственно сделанного), нормативного существования и функционирования, выражающего "естественную" природу человека, его "земную" сущность;

- мотивационный фактор как их движущую сияу и интересы, ценности и прочие субъектные качества и мерности, без чего они теряют свои предметные свойства.

Эти факторы выражают ценности, интересы своих социальньг (совместно функционируюших) компонентов, причём в различных этических, эстетических, этнических, коммуникационных,
Аингвистических и прочих формах. Э.А. Орлова поясняет сложность вопросов понимания социальных укладов на примерах функционирования городских и сельских их разновидностей. В их формировании участвуют потребности и интересы жильцов (жилая площадь, распоможение места проживания, состав воды и воздуха, доступность к благам услуг и пр.), производственные факторы (расположение в масштабах поселения, взаимодействие с другими производственными и экспиуатационными участниками, планирование и архитектура города и др.), государственные и муниципальные органы (разработка и соблюдение норм безопасности жизнедеятемьности, выполнение требований гражданских свобод населения, возможности активного освоения социально-культурных ценностей территории и т.п.). В совокупности эти компоненты создают основу дия формирования и функционирования экологии города (экомогии поселения). Она не может быть отнесена Аишь к хозяйственному, духовно-нравственному, бытовому или какому-то одному из других компонентов жкизнедеятемьности чемовека и составляет социальную среду уклада жизни $[7$, с. 46-65]. Исходя из этого, современные масштабные реновации в муниципальньх преобразованиях г. Москвы по "сносу пятиэтажек" следует расценивать не только ках начальные этапы коренных социально-культурных изменений поселенческих укладов жизни в этом городе, но и в стране в целом.

УкАады жизни взаимодействуют со стилем жизни, образом жизни, качеством жизни, характером жизни, стратегией жизни, жизненными путями и ориентирами мюдей, другими подобными элементами жизнехарактеризующего инструментария и образуют с ними своеобразный камплекс средств, отражающий меняющуюся среду жизнедеятельности мюдей. Исследователи отмечают, что в современньх условиях "нарастает" состав средств, выражающих социальность жизнедеятельности мюдей. С особой остротой эти процессы проявАяются в нормативных, ценностныг и смысловых сферах жизнедеятельности мюдей [4]. С социальной и гражданской точек зрения недопустимо, чтобы социальноукмадные 
факторы жизнедеятельности мюдей становились препятствиями в их культурном развитии, они относятся $\mathbf{R}$ гАобаАьным финансово-экономическим, геополитическим, административно-управленческим ими другим управленческим или самоуправленческим структурам, к рассогласованности их взаимодействия. Все они находятся в среде своей жизнедеятеньности и открыты дмя своего взаимодействия и сотрудничества.

2. Укиады как миры человека: состав компонентов соииально-культурных укладов жизнедеятельности людей. В организационных и исследоватеиьских процессах необходимым этапом их становцения выступают процедуры онтомогизации ими, "проще" говоря, их формирования ("конституирования") впиоть до определения (дачи) названия (имянаречения). Таким путем создаются миры укладов, предпомагающие опредемение состава компонентов, их объёма, друтих композиционных факторов [6, с. 165-181].

Социальные уклады явмяются продуктом жизнедеятемьности мюдей и нуждаются в процедурах их формирования (проектирования, конструирования, производства, оптимизации и пр. действий). На протяжении диитемьного времени социальные укиады находимись под вмиянием интуитивной деятемьности мюдей или под решаюшим воздействием некоторых сочиальных гpупn (сословий, институтов и других специализированнњх субъектов). Зачастую целевоеипрочее содержательное взаимодействие между ними было слабо согиасовано, что служиио предпосыцками возникновения социамьньг, экономических и прочих противоречий, конфмиктов. Пагубными дия всего человечества стали разрывы между технологическими и гуманитарными укладами жизни, растушие разиичия качества жизни у богатьгх и бедных слоёв населения, искмючитемьные возможности представителей некоторьх социальных укмадов в приоритетном испомьзовании наличных средств, свобод и прав. Ненаучныт, иррационамьные стили управцения порождают и воспроизводят в расширенных масштабах опасные угрозы и риски жизнедеятельности. В результате чего Аюди начинают психомогически негативно воспринимать окружающую их социальную действительность, опасаются предпринимать активные созидательные действия. В обществе и её структурах сформировалась ситуация, которая предполагает намичие иной среды и других правии поведения и деятемьности: иных укладов жизни, освобождённых от социальной агрессии; иррациональньг и интуитивньх форм управмения. Одновременно от науки и рациональных форм деятемьности ожцдается принятие на себя иных задач управмения обществом, в том числе и в сфере организации социальньх укмадов. Некоторые специамисты в области социальных и политических наук считают, что к настоящему времени накопиен значительный потенциал знания в области управцения обществом, всех сфер его жизнедеятельности и на различных уровнях. Состояние социально-политического управмения уже не может ограничиваться томько объяснением социальной реальности, оно домжно активно участвовать в её прогнозировании и конструировании, основываясь на учёте условий функционирования имеющихся ресурсов в системе "чемовек - общество - природа" [4, с. 467]. На этой парадигме идей предпомагается создавать стратегию устойчивого развития нашей страны и её регионов, считая, что "современная социально эффективная политика не может не выстраиваться по строгой форме социально-помитического конструирования".

Рассматривая деятельность в области разработки исследоватемьских задач и их практической реализации полезной, мы, 6 npuнuиne, сомидарны с механизмом их решения. В качестве собственных действий считаем необходимым отметить два условия участия в такой деятельности:

- первое: прокомментировать "полезность" некоторьх используемьг в истории социальных укладов, прежде всего в России, их последовательность и содержание;

- второе: высказать своё видение дамьнейшего возможного процесса развития (эвоцюции) социацьных укиадов в некоторьгх сферах жизни России и в её Дальневосточном регионе.

Считаем, что социально-куиьтурные укцады формировамись по своей гсуиностин и укреплякись исторически в размичных последоватемьностях, в которьг 
не смогма выразиться обшая её логика. Да её и не могмо быть, поскольку речь в них идёт о размичных сущностных проиессах: природных, естественных, космических, земных, растительных, животных, микробиологических, человеческих, вещественных, энергетических, инорормационных и пр. Поэтаму, сообразно практике формирования укладов, в т.ч. и социальных, ход освоения ими сфер жизни мюдей происходим размичными способами. Отсюда и существенные "нестыковки" как в практике освоения и выражения социальной и другой действительности их укладами, так и в истории понимания процессов их развития (язычества, мифологий, религий, наук, искусств, техномогий и пр.). Первыми понятиями этих процессов дия рационалистических миропониманий должны быть "миры чемовека", которые содержат в себе все другие миры (миры растений, миры животньг, миры мюдей, миры космоса и т.д.), из которых "вытекают" понятия "мир жизни" и "уклад жизни".

В "укладной" практике и теоретикомогических исследованиях в термин "жизнъ" вкладывается содержание некоторой сферы (области, способа) организации мюдей, направменной на воспроизводственную, поведенческую, коммуникационную и другую деятельностную сторону функционирования мюдей, рассматриваемую, прежде всего, с точки зрения среды их жизнедеятельности, её условий и практических результатов. Основаниями её выступают как интуитивистская, так и целенаправменная деятемьность, мотивированная потребностями, интересами, ценностями и прочими детерминантами жизни, реализуемыми через обычаи, традиции, административные и прочие организационные механизмы, функционирующие в бытовой, семейной, хозяйственной, образовательной, игровой и других сфеpax их жизненных миров. В этом смысле термин "жизнь" прочно вошёц в практику мифологии, религии, художества, бытовых коммуникаций, прозы и поэзии, драматургии, фимософии, науки и многих других форм творчества.

Исходя из этой могики приоритетности - массовидности - бытия, следует обратиться к терминам, характеризую- щим интуитивно или явно (осмысленно) его постоянство, устойчивость, непрерывность. Хорошо подходит дАя этих целей термин "воспроизводство", ориентируюшийся на факт возобновцяемости условий жизнедеятельности. Он приобрём больиий авторитет в сравнении с терминами вживания, врастания и некоторыми другими, в т.ч. и вследствие удобного толкования в нём процесса изменчивости исходного состояния анамизируемой системы. В настоящее время воспроизводственные процессы, бесспорно, занимают ведущее место в исследованиях социальньгх укладов, касается это хозяйственно-экономических, демографических, технологических, экоАогических или многих иных состояний природы и общества. Считаем, что компонент "воспроизводства" нуждается и в дальнейшей доработке, дополнении с точки зрения фиксации начальных (исходных) состояний бытия миров природы, человека, жизни и др. Особенной важностью выступают способы (формы) выражения воспроизводственных настроений, действий, поведений. На социальноукмадных уровнях воспроизводственные процессы зачастую приобретают противоречивый вид, "экстравагантно" выражаясь в формах патриотических дум, снов, бымин, мечтаний, утопий, фантазий и прочих подобных явлениях. Широко распространенной формой выражения процессов воспроизводства мюдей (их рождений, проблематики жизни, прочих её ситуаций) в России была песня. В песнях выражались настроения народа, его думы, тревоги, мечты, заботы и пр. Дальневосточный учёный, мысмитель и неравнодушный человек М.И. $\Lambda$ еденев, прекрасно выразил свои мысли о понимании жизни нашей страны в её нынешней ситуации в работе «Почему Россия петь перестала". В ней он ставит вопросы о жизни трудового народа, о государственном обустройстве её в нашей стране, ответственности каждого человека о её защите и приумножении, о задачах и уроках на будущее бытие и пр. Особенно остро эти вопросы звучат в его работе "Верна ми моция?", входящей в ту же "серию" произведений автора. Прямо и конкретно им формулируются проблемы государственного и гражданственно- 
го освоения Дальнего Востока как дамьневосточной российской территории [5].

Заботясь о сохранении и развитии постоянства, устойчивости и непрерывности воспроизводственных процессов как исходных состояний социальных укцадов, выберем из всей "массы" социальной действительности (бытия) компоненты производства как реального способа их достижения. В современных условиях производство как инструмент достижения постоянства, устойчивости и непрерывности, да ешё и в расши ренных масштабах, подлежит достаточно компетентным уровням управцения (технологиям менеджмента). Оно хорошо освоено практикой общественного управцения, поскольку входит в состав реально сформировавшихся и исторически освоенных человечеством социальных укладов. Оно находится преимущественно в сфере общественного управления как по содержанию процессов производства, их объемов, так и темпов, тенденций и многих других параметров. Исключения составляют преимущественно отдельные антропомогические, социально-гуманитарные и психомогические объекты.

Дальнейшее освоение категорий постоянства, устойчивости и непрерывности направляет наш интерес $\mathbf{k}$ поиску причинно-следственншгх оснований социального бытия и потребностей производства (воспроизводства). Эти аспекты методомогии исторически многообразно и разнообразными способами выражены социальными укладами. Следует обозначить многочисленные способы "собирательства" вплоть до "побирушничества" и не менее "изобретательные" формы "присвоения" чужого добра (имуuества) впиоть до воровства, обманов, вымогательств, захватов и т.п. В социальных уложениях возникает прочное "срастание" на нравственной основе категорий "добра" и "богатства", которые, к тому же, ещё и эстетизируют, и приобретают административное "бцагословение». В этом ряду особую значимость приобретает феномен $m p y д a-$ трудовой формы занятости. Четкость и её достойность выражены ужке в мифологическом сюжете Акипия Киавдия Цеха, с именем которого связывается выражение спо- собности человека контролировать свою судьбу и своё окружение в процессе труда (работы). Считается, что похищение Прометеем огня из кузницы Гефеста поможило начало традиции осознанного формирования трудового образа жизни как наиболее достойного дмя человека: каждый сам кузнец своей судьбы $[10$, с. 14-15 ]. И боги наказали его не за огонъ, а за характер приобретения этого важнейшего средства жизнеобеспечения чемовечества - за похищение. Сюжет роли труда (трудового образа жизни, трудовой формы занятости) в социальных укладах выражен и романтически (поэтически, благообразно), и трагически (безобразно): такова уж противоречивая правдивая судьба социальных укладов.

Уже на данном уровне социальной организации общества хорошо обнаруживается её глубокая композиционность (комплексность, системность, синергийность), что проявцяется и в функционировании социальных укладов. Одна из наиболее острых форм этой противоречивости выражается в принципиальной нерешенности вопроса о соотношении "индивидуальности" и "коллективности" человека. Жизнь, её практика бесспорно доставляют аргументы о социальном (совместном) характере труда. Социальность трудовой деятельности подтверждается её экономической, технологической, организационной, психологической и многими другими аспектами. Отдемьные из них находят подобное подтверждение и на био-антропологическом уровне $[1$, с. 3-4]. Вместе с тем продолжаются упорные утверждения о приоритетности индивидуальных свойств человека и даже уникальности каждой мичности. Не оспаривая этих утверждений "в цемом", следует более четко в методомогическом отношении дифференцировать вопросы о соотношении индивидуальности и совместности человека. Негативные проблемы будут возникать не вследствие того, что все Аюди станут мишь сугубо индивидуальными или сугубо групповыми, а вследствие нечеткого собственного поведения кахдым в своих мичных ситуациях, а также "нечеткости" обозначения этих позиций в общественньх укладах (экономических, технологических, социамьных, психологических и др.). 
Подобные противоречивые ситуации сформировались и в других социальных укладах. Обратимся к такому как семья (семейственность, семейный образ жизни, семейный уклад жизни). Не будем обсуждать все сложности семейственного уклада жизни, они богато и глубоко выражены в жизнедеятельности последних мет народов Европы и мигрантов на её территорию из Африки и Азии. Обратимся $\mathbf{k}$ источнику, который домгое время добросовестно служии многим россиянам своеобразным эталоном в умаживании ими семейньгх дем и ориентиром в принятии решений по этим вопросам. Речь пойдёт о Домострое. Полное название этого уникального произведения XVI века "Книга, называемая Домостроем, которая содержит в себе полезные сведения, поучение и наставление всякому христианину - и мужу, и жене, и детям, и слугам, и служанкамж. Со времени создания и до появАения на российской общественной сцене революционньг демократов она была авторитетным сборником по вопросам социальньх уложений. В последующем стала подвергаться массированной критике, её постулаты стали объявАяться косными, тормозяшими общественный прогресс $[8$, с. 3]. Но стоит ми так однозначно всякому россиянину негативно расценивать завещания нам Виадимира Мономаха, наставмения отца сыну, поучения о воспитании детей своих, советы им - мюбви отца и матери, о рукодельничании всякого человека, о похвалах жёнам, о мучшем обустройстве избы и наведении порядка в ней и другие подобные пожемания. Многие из отмеченных пожеманий перешии сегодня в содержание курсов по домоведению, в положения о планировании семьи и др. Но они в своей основе не потеряли актуальности и продолжают интересовать активных и заботливых граждан, беспокоящихся о собственном соииальном благополучии, а не выставляющих претензии работникам социальных и муниципальньх служб, что их нвовремя" не предупредили о необходимости наведения санитарно-гигиенического порядка в собственной квартире или о требованиях надлежащего присмотра за своими детьми. Бесспорно, современная семья далека от "того" домостроя, но и каждый из нас тоже уже ждругой и далжен бъть способ- ным оценивать подобные изменения.

Аналогичные аспекты методомогии анализа социальных укцадов, как показывает приведенное обращение к ним, нуждаются в глубоком заинтересованном самостоятельном дополнительном систематизированном исследовании.

3. Актуальные задачи исследования социальных укладов в современной России. Отмеченные задачи полезно подразделить по характеру их содержания. Bo-первьх, нужны действия, направленные на их актуализацию, на привлечение внимания к ним. Дия этого нужны и организованные кампании по формированию тематики исследований, и дополнительные мероприятия. Например, использовать в качестве организационных мероприятий Конкурс президентских грантов НКО, запущенный 14 апреля 2017 г. "Об обеспечении в 2017 году государственной поддержки некоммерческих неправительственных организаций, участвующих в развитии институтов гражданского общества, реализуюших социально значимые проекты и проекты в сфере защиты прав и свобод человека и гражданина". В соответствии с ним в 2017 г. на поддержку некоммерческих неправительственных организаций из федерального бюджета выделяется 4,32 мирд. руб., которые будут распредемены по резумьтатам двух конкурсов. Проведение конкурсов и предоставление грантов поручено Фонду-оператору президентских грантов по развитию гражданского общества (Фонду президентских грантов).

Во-вторых, следует специально предусмотреть и продолжить действия по анализу состава социальньх укладов в стране и на её территории, их наличия и состояния, информационной базы о них и т.п. Так, дАя России и её Дальнего Востока смедует выдемять особый природно-климатический уклад, учитывающий, что наша страна территория северных пространств [9]. ДАя неё следует разрабатывать специфические жилищные нормативы, нормативы питания, поведения и прочие аспекты экалогии человека. Специфические экомогические методологические аспекты требуются и дАя других характеристик жизнедеятемьности северян, дамьневосточников, и не только их [3]. В социальных укладах рос- 
сиян, в т.ч. дальневосточников, широко представцены пространственные факторы жизнедеятельности, их отношений к природе и социально-экономической среде.

B-третьих, необходимо уделять специальное внимание вопросам формирования новой (инновационной) методомогии освоения мира: открытого мира, открытого мировоззрения, открытого поведения, открытого образования и т.д. Методология открытости в значительной мере меняет требования к правимам (принципам) и другим нормам исследовательского поведения. Так, зная о предмете своего исследования, исследователь соответствующим способом формирует его модемь, планируя какие из поставАенных вопросов следует оставцять иоткрытыми" и пр. Возможна и такая вариативность рассматриваемых вопросов, когда исследованию "подвергаются" наиболее "основательные" из них, например, о взаимодействии социальных и технологических укладов.

\section{Cnuсок литературы:}

1. Алексеев В.П. Человек: эволюиия и таксономия. Некоторые теоретические вопросы. М. : Наука, 1985. 287 c.

2. Болл Ф. Критическая масса. Как одни явления порождают другие. М. : Гелеос, Динаcmur, 2004. $528 \mathrm{c}$.

3. Дружкинин И.П. Жизнь человека - самый важный экологический критерий. Хабаровск, 1989. 22 c.

4. Аевашов В.К. Российское государство и обшество в период либеральных реформ начала XXI века. М. : LСПиМ, 2013, 456 c.

5. Меденёв М.И. Почему Россия петь перестала : сборник. Хабаровск, 2003. - 320 с.

6. Методология философии и науки в ситуаиии современной открытости миров // Методологические аспекты исследования философии и науки в современной России : монография. Хабаровск : Дальневосточный институт управления - филиал РАНХиГC, 2016. С. 165-204.

7. Орлова Э.А. Современная городская культура и человек. М. : Наука, 1987.

8. Пилипов В. Так ли плох был Домострой? М.
: Панорама, 1991. 48 с. (Популярная библиотечкаш «Коробейник". Серия "Для дома, для семьш).

9. Россия-страна северных пространств // Вестник ДВО 1992. № 1-2. С. 27-31.

10. Сидорина T.Ю. "Hото faber" как символ эпохи труда: к истории эволюиии понятия // Вопросы философии. 2015. № 3. C. 14-15.

11. Сухарев О.С. Институциональная экономика. М. : Издательство Юрайт, 2016. 501 c.

12. Теория и практика сочиальнополитического управления и конструирования // Вестник Российской академии наук. 2014. № 5. C. $465-468$.

\section{References:}

1. Alekseev V.P. CHelovek: ehvolyuciya $i$ taksonomiya. Nekotorye teoreticheskie voprosy. M. : Nauka, 1985. $287 \mathrm{~s}$.

2. Boll F. Kriticheskaya massa. Kak odni yavleniya porozhdayut drugie. M. : Geleos, Dinastiya, 2004. $528 \mathrm{~s}$.

3. Druzhinin I.P. ZHizn'cheloveka-samyj vazhnyj ehkologicheskij kriterij. Habarovsk, 1989. 22 s.

4. Levashov V.K. Rossijskoe gosudarstvo $i$ obshchestvo $v$ period liberal'nyh reform nachala HKHI veka. M. : CSPiM, 2013, 456 s.

5. Ledenyov M.I. Pochemu Rossiya pet' perestala : sbornik. Habarousk, 2003. - 320 s.

6. Metodologiya filosofii $i$ nauki $v$ situacii sovremennoj otkrytosti mirov // Metodologicheskie aspektyissledovaniyafilosofiiinaukivsovremennoj Rossii : monografiya. Habarovsk: Dal'nevostochnyj institut upravleniya - filial RANHiGS, 2016. S. 165-204.

7. Orlova EH.A. Sovremennaya gorodskaya kultura i chelovek. M. : Nauka, 1987.

8. Pilipov V. Tak li ploh byl Domostroj? M. : Panorama, 1991. 48 s. (Populyarnaya bibliotechka" "Korobejnik". Seriya "Dlya doma, dlya sem"i».

9. Rossiya - strana severnyh prostranstv // Vestnik DVO 1992. № 1-2. S. 27-31.

10. Sidorina T.YU. "Homo faber" kak simvol ehpohi truda: $k$ istorii ehvolyucii ponyatiya // Voprosy filosofii. 2015. № 3. S. 14-15.

11. Suharev O.S. Institucional'naya ehkonomika. M. : Izdatel'stvo YUrajt, 2016. $501 \mathrm{~s}$.

12. Teoriya i praktika social'no-politicheskogo upravleniya $i$ konstruirovaniya // Vestnik Rossijskoj akademii nauk. 2014. № 5. S. 465-468. 